\title{
Risk factors for multiple tobacco product use among high school youth
}

\author{
Amira Osman ${ }^{\mathrm{a}, \mathrm{b}, *}$, Sarah D. Kowitt ${ }^{\mathrm{c}}$, Leah M. Ranney ${ }^{\mathrm{b}, \mathrm{c}}$, Courtney Heck ${ }^{\mathrm{d}}$, Adam O. Goldstein ${ }^{\mathrm{b}, \mathrm{c}}$ \\ ${ }^{a}$ School of Nursing, Zefat Academic College, Zefat, Israel \\ ${ }^{\mathrm{b}}$ Lineberger Comprehensive Cancer Center, University of North Carolina at Chapel Hill, Chapel Hill, NC, United States \\ ${ }^{\mathrm{c}}$ Department of Family Medicine, University of North Carolina at Chapel Hill, Chapel Hill, NC, United States \\ ${ }^{\mathrm{d}}$ North Carolina Department of Health and Human Services, Division of Public Health, Tobacco Prevention and Control Branch, Raleigh, NC, United States
}

\section{H I G H L I G H T S}

- Intra and interpersonal factors are linked to youth multiple tobacco product use.

- Youth multiple product users have weaker tobacco-related harm perceptions.

- Youth multiple product users are more exposed to tobacco use by peers.

- Youth multiple product users are more exposed to secondhand e-cigarette vapor.

- Youth multiple product users are significantly more receptive to tobacco marketing.

\section{A R T I C L E I N F O}

Keywords:

Ecological models

Risk factors

Multiple tobacco product use

Dual use

Poly use

Youth

\section{A B S T R A C T}

Purpose: To examine how youth multiple tobacco product (MTP) users differ relative to non-users and to singleproduct users on risk factors at multiple levels of influence.

Methods: We analyzed data on high school students from the North Carolina Youth Tobacco Survey, 2015 $(n=2922)$. Single- and MTP use were defined as use of one, or two or more tobacco products in the past month, respectively. Multinomial regressions estimated the association between risk factors and MTP use compared to single-product use and non-use of tobacco. Risk factors included intra-personal (e.g., harm perceptions), and interpersonal (e.g., household, peer tobacco use, secondhand smoke or vapor, and advertising) factors.

Results: Of students, $12 \%$ and $13 \%$ were single product and MTP users, respectively. Many differences emerged between MTP users and non-tobacco users, with MTP users showing lower harm perceptions, higher perceived social benefits of smoking, significantly higher relative risk of having friends who use tobacco $(\mathrm{RRR}=4.79,95 \%$ CI 3.42, 6.70), of exposure to secondhand e-cigarette vapor (RRR $=1.35,95 \%$ CI $1.23,1.48$ ), and of being receptive to tobacco marketing ( $\mathrm{RRR}=4.01,95 \% \mathrm{CI} 2.87,5.61$ ). Fewer differences emerged between MTP and single product users with MTP users having significantly higher relative risk of having friends who use tobacco ( $\mathrm{RRR}=2.3195 \%$ CI 1.73, 3.07), of exposure to secondhand vapor (RRR $=1.10,95 \%$ CI 1.02, 1.18), and of being receptive to tobacco marketing ( RRR $=1.71,95 \%$ CI $1.17,2.50$ ).

Conclusions: Efforts that target multiple tobacco product use should increase youth tobacco-related harm perceptions, and protect youth from social, peer, and industry influences.

\section{Background}

Multiple tobacco product (MTP) use (i.e., use of two or more tobacco products concurrently) has recently become widespread among young people (Fix, O'Connor, Vogl, et al., 2014; Horn, Pearson, \& Villanti, 2016). Despite decreases in overall tobacco use in recent years, concurrent use of multiple tobacco products is high and is estimated at about 50\% among youth users of tobacco (Arrazola, Singh, Corey, et al., 2015; Soneji, Sargent, \& Tanski, 2016). In 2017, 19.6\% of high school students in the US (estimated 2.95 million users) were current users of a tobacco product, including $9.2 \%$ ( 1.38 million; $46.8 \%$ of current tobacco users) who reported the concurrent use of $\geq 2$ tobacco products (Wang, Gentzke, Sharapova, et al., 2018). Other studies have also estimated that the number of youth who concurrently use multiple

\footnotetext{
* Corresponding author at: 11 Jerusalem St., PO Box 160, Zefat 13206, Israel.

E-mail addresses: amira.os@zefat.ac.il, amirao@email.unc.edu (A. Osman), kowitt@email.unc.edu (S.D. Kowitt), Leah_Ranney@unc.edu (L.M. Ranney), Courney.Heck@dhhs.nc.gov (C. Heck), adam_goldstein@med.unc.edu (A.O. Goldstein).
} 
- Receptivity to tobacco marketing

- Exposure to tobacco ads on the internet

- Exposure to tobacco ads at point of sale
- Family members smoking

- Peer smoking

- Rules of smoking at home or family vehicle

- Exposure to others' smoking at home

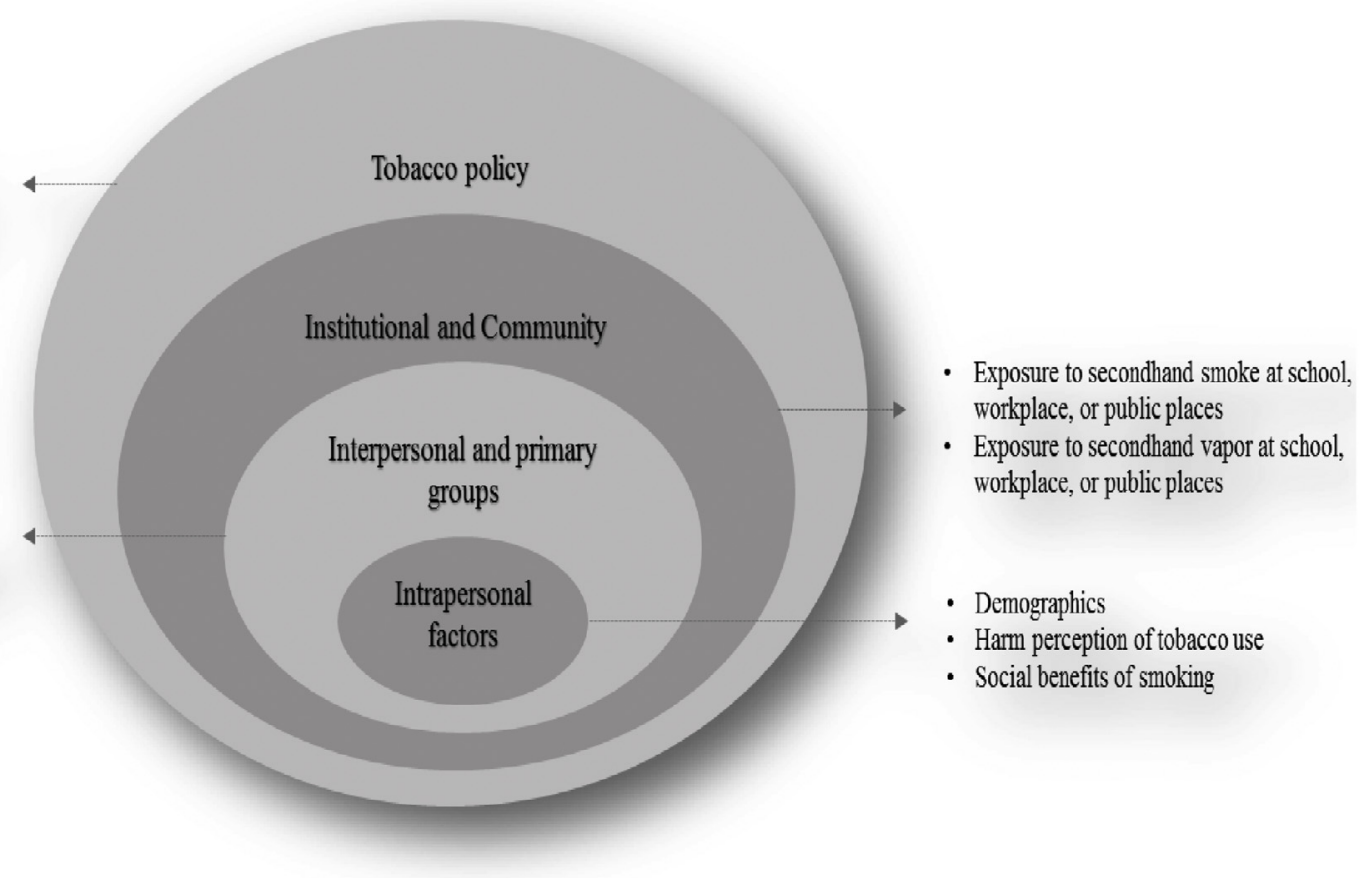

Fig. 1. Study ecological model representing factors at multiple levels of influence that impact tobacco use behavior.

tobacco products exceeds the number of youth who use a single product (Ali, Gray, Martinez, et al., 2016; Apelberg, Corey, Hoffman, et al., 2014; Kowitt, Patel, Ranney, et al., 2015; Nasim, Blank, Cobb, et al., 2012). Thus, it is important to understand the characteristics and risk factors associated with this behavior.

Use of any tobacco product during adolescence is harmful to health as nicotine exposure harms the developing brain and causes addiction (Ali et al., 2016; Apelberg et al., 2014; Dwyer, McQuown, \& Leslie, 2009; Tomar, Alpert, \& Connolly, 2010; Wetter, McClure, de Moor, et al., 2002). While no level of nicotine exposure is safe, use of multiple tobacco products concurrently exposes the developing adolescent brain to higher levels of nicotine relative to a single product use, thus exacerbates the risk for addiction and dependence. Indeed youth MTP users are more nicotine dependent and less likely to intend to quit using tobacco than single product users (Ali et al., 2016). This early-age dependence on nicotine increases the risk that youth MTP users will continue using tobacco well into adulthood. In addition, exposure, at a young age, to harmful and potentially harmful constituents and carcinogens from multiple combustible (e.g., cigarettes) and non-combustible tobacco products (e.g., smokeless tobacco) increases the risk for immediate and long term negative health effects associated with tobacco use (Baker, Ainsworth, Dye, et al., 2000; Teo, Ounpuu, Hawken, et al., 2006).

MTP use in youth is likely driven by the rise in OTPs (i.e. other tobacco products than cigarettes) in the U.S market, particularly those that offer enticing flavors such as e-cigarettes, and hookah (Benowitz, 2014; Lauterstein, Hoshino, Gordon, et al., 2014). A myriad of other potentially modifiable intra- and interpersonal risk factors, however, remain understudied. As a first step to dealing with this issue, studies are needed to characterize users and to identify risk factors associated with this behavior. Consistently studies show that, demographically, MTP use is more common in older, male, Hispanic and non-Hispanic White youth (Ali et al., 2016; Kowitt et al., 2015; Osman, Kowitt, Ranney, et al., 2018). In comparison to single product users and nonusers of tobacco, MTP users have weaker harm perceptions of different tobacco products, (Ali et al., 2016; Cooper, Creamer, Ly, et al., 2016; ElToukhy \& Choi, 2016) and are more likely to believe that young people who smoke have more friends (Ali et al., 2016). Also, at the
Intrapersonal level, MTP use is positively associated with sensation seeking in youth (Soneji et al., 2016). Other potentially influential factors are those related to the social environment as it relates to tobacco use. For example, Ali, et al., (2016) found that MTP users were more likely than single product users to smoke a cigarette if offered by a friend (Ali et al., 2016) Cooper et al., (2016) found that MTP users differed from single-product users most notably in their higher perceived use of tobacco products by close friends and dating partners (Cooper et al., 2016). At a higher level of influence, few studies have examined receptivity to tobacco promotions as a determinant of youth use of OTPs (Gilpin \& Pierce, 2003; Mantey, Cooper, Clendennen, et al., 2016; Pierce, Sargent, Martha, et al., 2017). Consistent with that, it has been shown in two previous studies that MTP users, among which OTP use is high, are more receptive to tobacco marketing than their counterparts (El-Toukhy \& Choi, 2016; Lee, Hebert, Nonnemaker, et al., 2015). The vast majority of the aforementioned studies have examined primarily intrapersonal factors such as harm perceptions; and only few have examined factors at higher levels of influence (familial, community, or marketing).

In this study, we take an ecological model approach to examine variables at multiple levels of influence that may be associated with MTP use in North Carolina (NC) youth. The core premise of ecological models is that behaviors and behavior change are driven by factors at multiple levels of influence (intrapersonal, interpersonal, organizational, community, and policy factors) that are important to study. The model provides a comprehensive framework for understanding determinants of health behavior to inform the development of interventions that systematically target factors at each level of influence (Sallis, Owen, \& Fisher, 2015). The factors we examine include intrapersonal (harm perceptions and beliefs about the social benefits of tobacco use), interpersonal (family and peers influences), community (exposure to smoking and vaping at community settings), and exposures to tobacco marketing and advertising (Fig. 1). Results may inform tobacco prevention efforts that directly target the public health issue of MTP use in NC youth. The state of NC presents one of the highest youth smoking rates in the nation at $12.1 \%$ (Campaign for Tobacco Free Kids, 2019). It is also the nation's leading tobacco-growing and -manufacturing state, with over 1680 active tobacco farms (Campaign for Tobacco Free Kids, 
2014). In addition, NC has some of the weakest tobacco control policies in the nation and the fifth lowest cigarette excise tax at $\$ 0.45$ per cigarette pack (Campaign for Tobacco Free Kids, 2019). NC also has a statewide preemption regulation that blocks the passing of strict clean indoor air laws. In recent years, funding cuts to the statewide Teen Tobacco Use Prevention and Cessation Initiative have been threatening the delivery of community and school-based programs for youth, focused on education, prevention, and policy change to reduce tobacco use (McCullough, Ranney, Simons, et al., 2018). These factors put NC youth at a higher risk of tobacco-related exposures, behaviors, and illnesses.

\section{Methods}

We analyzed data on high school students from the 2015 Wave of the North Carolina Youth Tobacco Survey (NC YTS), a repeat cross sectional, public and charter school-based survey, administered every two years since 1999, and includes middle and high school students (NC Health and Human Services, 2019). The survey used a multi-stage cluster sampling design in three regions of the state (West, Central, and East). Within each region, schools were first selected with probability for selection proportional to the school's enrollment size, and then classes were randomly selected within each school. Passive consent forms were utilized, unless an active consent form was required by the school policy. The overall response rate was $74.4 \%$.

For this study, we analyzed data on high school students $(n=3420)$. We excluded Middle school students from the analyses because of small sample size of tobacco product users. Students with missing values on study variables were excluded $(n=498)$ resulting in a final analytic sample of $n=2922$ students. This study uses secondary data analyses and does not constitute human subjects research as defined under federal regulations 45 CFR 46.102 (d or f) and 21 CFR 56.102(c)(e)(l), hence, did not require an institutional review board approval.

\subsection{Measures}

\subsubsection{Non-use, single, and multiple tobacco product (MTP) use}

The survey assessed past month use of ten tobacco products including: cigarettes (including roll your own and flavored cigarettes); cigars (including cigars, little cigars, flavored cigars, and cigarillos); waterpipe; pipe tobacco; bidis; clove cigarettes (Kreteks) or clove cigars; electronic cigarettes; smokeless tobacco (SLT) (including chewing tobacco, snuff, or dip); snus, and dissolvable tobacco. Students were classified as current users of a product if they indicated using it on at least one day in the past month. Then an index of tobacco product use was created by summing up the number of tobacco products used in the past month (Minimum $=0$, Maximum $=10$ ). Students were then classified as (1) non-users if they did not use any of these tobacco products, (2) single product users if they used only one tobacco product, and (3) multiple tobacco product (MTP) users if they used two or more tobacco products.

\subsubsection{Individual level factors}

2.1.2.1. Harm perceptions of tobacco, cigarettes, and e-cigarettes. Three questions assessed students' perceptions of tobacco product harms (1) How strongly do you agree with the statement: All tobacco products are dangerous? (' $0=$ strongly agree/agree', ' $1=$ strongly disagree/ disagree'), (2) Do you think that breathing smoke from other people's cigarettes or other tobacco products is?, and (3) Do you think that breathing vapor from other people's electronic cigarettes is? Responses to the latter two questions were coded as ' $0=$ very or somewhat harmful', ' $1=$ not very harmful or not harmful at all'.

2.1.2.2. Perceived social benefits of smoking. Students were asked (1) Do you think smoking cigarettes makes young people look cool or fit in?, and (2) Do you think young people who smoke cigarettes have more friends? Responses were coded as ' $1=$ definitely or probably yes', ' $0=$ probably or definitely not'.

Individual level factors also included demographic variables of age, sex, race, and amount of weekly discretionary income the student spends as covariates.

\subsubsection{Household and peer social influences}

2.1.3.1. Smoking rules at home, family and peer smoking. Several questions assessed self-reported exposure to smoking in the student's social environment. Student were asked whether smoking is allowed (1) inside their home and (2) in the vehicles that they and family members own or lease, and were coded as ' $1=$ smoking allowed in home or vehicle' or ' $0=$ smoking not allowed in either'. A third question assessed current use of 9 tobacco products by those who live with the student (i.e., cigarettes; cigars, cigarillos, or little cigars; smokeless tobacco; electronic cigarettes; waterpipe; tobacco pipe; snus; bidis; or dissolvable tobacco). Students were coded as having family members who ' $0=$ do not use any product', ' $1=$ use one product', and ' $2=$ use $2 \geq$ products'. Lastly, student were asked how many of your four closest friends (1) smoke cigarettes and (2) Chew tobacco and were coded as ' $0=$ not having' or ' $1=$ having' friends who smoke or chew tobacco.

2.1.3.2. Self reported exposure to other people smoking behavior at home or in vehicle. Students were asked during the past 7 days, on how many days (1) did someone smoke tobacco products in your home while you were there? And (2) did you ride in a vehicle where someone was smoking a tobacco product? ( 0 days to 7 days). The two items were moderately correlated $(r=0.52)$ and were averaged.

\subsubsection{School, work, and community environments}

2.1.4.1. Self-reported exposure to secondhand smoke in school, workplace, or public places. Students were asked during the past 7 days, on how many days did you breathe the smoke from someone who was smoking a tobacco product (1) at your school, (2) in the place where you work, and (3) in an indoor or outdoor public place?. Responses were 0 days to 7 days and were averaged across the three items.

2.1.4.2. Exposure to secondhand e-cigarette vapor in public places. Students were asked during the past 7 days, on how many days did you breathe the vapor from someone who was using an electronic cigarette in an indoor or outdoor public place?. Responses were 0 days to 7 days.

\subsubsection{Receptivity and exposure to tobacco advertising}

2.1.5.1. Receptivity to tobacco advertising. Students were asked: How likely is it that you would ever use or wear something (such as a lighter, T-shirt, hat, or sunglasses) that has a tobacco company name or picture on it? Responses were coded as ' $1=$ very or somewhat likely' and ' $0=$ somewhat or very unlikely'.

2.1.5.2. Exposure to tobacco advertising. This was measured using two items, (1) when you are using the Internet, how often do you see ads for tobacco products, including electronic cigarettes?, and (2) when you go to a convenience store, supermarket, or gas station, how often do you see ads or promotions for cigarettes and other tobacco products? Responses were coded as ' $0=$ never or rarely', ' $1=$ sometimes, most of the time or always'.

\subsection{Statistical analysis}

We began with descriptive statistics to understand the data distributions and to describe the demographic characteristics of students who participated in the 2015 NC YTS. Using chi ${ }^{2}$ tests, we examined differences in age, sex, and race distributions between non-users of tobacco, single, and MTP users (Table 1). Then, for each tobacco 
Table 1

Demographic characteristics of students, NC YTS, 2015, weighted estimates.

\begin{tabular}{|c|c|c|c|c|c|}
\hline & Total sample $(n=2922)$ & Non tobacco users $(n=2191)$ & Single product users $(n=356)$ & Multiple product users $(n=375)$ & $P$ value \\
\hline Age & $\%$ & $\%$ & $\%$ & $\%$ & \\
\hline 14 or less & 20 & 22 & 11 & 11 & 0.000 \\
\hline 15 & 27 & 29 & 22 & 22 & \\
\hline 16 & 24 & 24 & 27 & 22 & \\
\hline 17 or older & 29 & 25 & 40 & 45 & \\
\hline \multicolumn{6}{|l|}{ Sex } \\
\hline Male & 49 & 47 & 51 & 63 & 0.000 \\
\hline Female & 51 & 53 & 49 & 37 & \\
\hline \multicolumn{6}{|l|}{ Race } \\
\hline Non-hispanic White & 55 & 52 & 57 & 68 & 0.0025 \\
\hline Non-hispanic Black & 25 & 27 & 23 & 16 & \\
\hline Hispanic & 13 & 13 & 13 & 11 & \\
\hline Non-hispanic other & 7 & 8 & 7 & 5 & \\
\hline \multicolumn{6}{|c|}{ Student's weekly discretionary income } \\
\hline$\$ 1-10$ & 29 & 32 & 21 & 17 & 0.000 \\
\hline$\$ 11-20$ & 20 & 20 & 22 & 15 & \\
\hline$\$ 21-50$ & 20 & 20 & 17 & 26 & \\
\hline$\$ 50+$ & 31 & 28 & 40 & 42 & \\
\hline
\end{tabular}

Note. $P$ values are based on $\mathrm{chi}^{2}$ test of differences between non-users, single product users, and multiple product users.

Table 2

Percentages of users of each tobacco product by use categories.

\begin{tabular}{llll}
\hline Tobacco Products & $\begin{array}{l}\text { Tobacco users } \\
(n=731)\end{array}$ & $\begin{array}{l}\text { Single product } \\
\text { users }(\mathrm{n}=356)\end{array}$ & $\begin{array}{l}\text { Multiple product } \\
\text { users }(\mathrm{n}=375)\end{array}$ \\
\hline \% users & $\%$ users & $\%$ users \\
\hline E-cigarettes & 64 & 52 & 76 \\
Cigarettes & 46 & 22 & 69 \\
Cigars (including & 32 & 9.5 & 55 \\
$\quad$ cigarillos) & & & \\
Smokeless tobacco & 23 & 9 & 37 \\
Pipe tobacco & 15 & 5 & 26 \\
Hookah & 12 & 2 & 23 \\
Bidis & 5 & 0.3 & 9 \\
Clove cigarettes & 6 & 0.4 & 12 \\
Snus & 6 & 0 & 12 \\
Dissolvable tobacco & 2 & 0 & 3.5 \\
\hline
\end{tabular}

product, we examined the percentage of youth users across single and MTP users (Table 2).

We estimated multinomial multiple regression models to examine the association between all independent variables and MTP use (Table 3). The models were estimated twice, first comparing MTP users to non-users of tobacco products, and second comparing them to single product users. Independent variables included: individual level factors (i.e., demographics, harm perceptions, perceived social benefits of smoking), household and peer social influences, school, work, and community related exposures, and receptivity and exposure to tobacco advertising variables. All models adjusted for age, sex, race, and student's weekly discretionary income. We present relative risk ratios (RRR) and their associated confidence intervals. Analyses were conducted using STATA version 13 and were weighted to account for the complex survey design and sampling weights.

\section{Results}

\subsection{Sample characteristics}

Of students, $25 \%$ were tobacco users, and $12 \%$ and $13 \%$ were single product and MTP users, respectively (Table 1 ). Statistically significant differences emerged between non-users, single, and MTP users by demographic characteristics. A higher percentage of youth MTP users were 17 years or older, male, and White, than youth non-users and single product users.

\subsection{Products used}

Among youth single product users, $52 \%$ used e-cigarettes and $22 \%$ used cigarettes in 2015 (Table 2). Among MTP users, over two thirds reported using e-cigarettes (76\%) and cigarettes (69\%), over a half used cigar products (55\%), and over a fourth reported using smokeless tobacco $(37 \%)$, pipe tobacco $(26 \%)$, and hookah $(23 \%)$.

\subsection{Risk factors for multiple tobacco product use}

Relative to non-users (Table 3, Model 2), MTP users had higher relative risk of disagreeing that all tobacco products are dangerous (RRR $1.79,95 \%$ CI 1.01, 3.18), of believing that exposure to secondhand vapor is not harmful (RRR 1.79, 95\% CI 1.32, 2.45) and of believing that smokers are cool (RRR 1.70, 95\% 1.11, 2.61). MTP users had higher relative risk than non-users of having family members who use tobacco products (RRR 1.51, 95\% CI 1.01, 2.26) and about five times higher relative risk of having friends who use tobacco (RRR 4.79, 95\% CI 3.42, 6.70). MTP users also had a higher relative risk of exposure to others smoking in their presence at home or while riding a vehicle (RRR 1.19, 95\% CI 1.09, 1.30). Adjusting for all aforementioned factors, there was no difference in exposure to secondhand smoke in public places between MTP and non-tobacco users. MTP users, however, had higher relative risk than non-users of exposure to secondhand vapor in public places (RRR 1.35, 95\% CI 1.23, 1.48) and about 4 times higher relative risk of being receptive to tobacco marketing items (RRR 4.01, 95\% CI 2.87, 5.61).

In comparison to single product users, MTP users had a significantly higher relative risk of having friends who use tobacco (RRR 2.31, 95\% CI 1.73, 3.07). Further, MTP users were no different from single product users in their exposure to secondhand smoke in public places but had significantly higher relative risk of exposure to secondhand vapor in public places (RRR 1.10, 95\% 1.02, 1.18) and of being receptive to tobacco marketing items (RRR 1.71, 95\% CI 1.17, 2.50). There were no statistically significant differences between MTP users and single product users in harm perceptions of tobacco use, the belief that smokers are cool or have more friends, the risk of having family members who use tobacco, or the risk of having household rules that allow smoking (Table 3, Model 3).

\section{Discussion}

This study, informed by an ecological model approach, examined risk factors at multiple levels of influence that may be associated with 
Table 3

Relative risk ratios and 95\% confidence intervals from multiple multinomial regression models, NC YTS, 2015 (n = 2922).

\begin{tabular}{|c|c|c|c|}
\hline & $\begin{array}{l}\text { Single Product Users Vs. } \\
\text { Non-Tobacco Users }\end{array}$ & $\begin{array}{l}\text { Multiple Product Users } \\
\text { Vs. } \\
\text { Non-Tobacco Users }\end{array}$ & $\begin{array}{l}\text { Multiple Product Users } \\
\text { Vs. } \\
\text { Single Product Users }\end{array}$ \\
\hline & Model 1 & Model 2 & Model 3 \\
\hline Individual Level Factors & RRR (95\%CI) & RRR (95\%CI) & RRR $(95 \% \mathrm{CI})$ \\
\hline \multicolumn{4}{|l|}{ Harm Perceptions } \\
\hline \multicolumn{4}{|l|}{ Tobacco products dangerous } \\
\hline Disagree vs. agree & $1.55(0.90,2.64)$ & $1.79(1.01,3.18)^{*}$ & $1.15(0.72,1.84)$ \\
\hline \multicolumn{4}{|l|}{ Harm perception of secondhand smoke } \\
\hline Not harmful vs. harmful & $1.10(0.55,2.16)$ & $1.08(0.58,2.05)$ & $0.99(0.64,1.55)$ \\
\hline \multicolumn{4}{|l|}{ Harm perception of secondhand vapor } \\
\hline Not harmful vs. harmful & $1.86(1.35,2.54)^{* * *}$ & $1.79(1.32,2.45)^{* * *}$ & $0.96(0.65,1.45)$ \\
\hline \multicolumn{4}{|l|}{ Perceived Social Benefits of Smoking } \\
\hline \multicolumn{4}{|l|}{ Smokers are cool } \\
\hline Yes vs. No & $2.24(1.52,3.31)^{* * *}$ & $1.70(1.11,2.61)^{*}$ & $0.76(0.52,1.11)$ \\
\hline \multicolumn{4}{|l|}{ Smokers have more friends } \\
\hline Yes vs. No & $0.94(0.64,1.40)$ & $1.20(0.86,1.67)$ & $1.27(0.81,2.00)$ \\
\hline \multicolumn{4}{|l|}{ Household and Peer Influences } \\
\hline \multicolumn{4}{|l|}{ Family members smoke } \\
\hline One product vs. None & $1.09(0.81,1.47)$ & $1.51(1.01,2.26)^{*}$ & $1.37(0.84,2.22)$ \\
\hline Two or $>$ products vs. None & $1.24(0.75,2.03)$ & $1.83(0.99,3.26)$ & $1.47(0.75,2.89)$ \\
\hline \multicolumn{4}{|l|}{ Have friends who smoke } \\
\hline Yes vs. No & $2.07(1.54,2.89)^{* * * *}$ & $4.79(3.42,6.70)^{* * *}$ & $2.31(1.73,3.07)^{* * *}$ \\
\hline \multicolumn{4}{|l|}{ Smoking rules at home or family vehicle } \\
\hline Smoking allowed vs. Not allowed & $1.67(1.13,2.49)^{*}$ & $1.37(0.96,1.96)$ & $0.82(0.53,1.25)$ \\
\hline Exposure to smoking behavior of others at home or in vehicle & $1.09(1.02,1.15)^{*}$ & $1.19(1.09,1.30)^{* * *}$ & $1.09(0.99,1.20)$ \\
\hline \multicolumn{4}{|l|}{ School, Work, and Community Exposures } \\
\hline Exposure to secondhand smoke in school, workplace, or public places & $1.02(0.84,1.23)$ & $1.12(0.95,1.32)$ & $1.10(0.94,1.28)$ \\
\hline Exposure to secondhand vapor in school, workplace, or public places & $1.22(1.11,1.35)^{* * *}$ & $1.35(1.23,1.48)^{* * *}$ & $1.10(1.02,1.18)^{* * *}$ \\
\hline \multicolumn{4}{|l|}{ Receptivity to and Exposure to Marketing } \\
\hline \multicolumn{4}{|l|}{ Wear things with tobacco industry logo/ ads } \\
\hline Likely vs. Unlikely & $2.34(1.65,3.32)^{* * *}$ & $4.01(2.87,5.61)^{* * *}$ & $1.71(1.17,2.50)^{* *}$ \\
\hline \multicolumn{4}{|l|}{ Exposure to tobacco ads on internet } \\
\hline Sometime / always vs. never & $0.87(0.62,1.22)$ & $0.81(0.62,1.05)$ & $0.93(0.64,1.33)$ \\
\hline \multicolumn{4}{|l|}{ Exposure to tobacco ads in stores } \\
\hline Sometime / always vs. never & $0.65(0.43,1.01)$ & $1.06(0.60,1.86)$ & $1.62(1.01,2.61)^{*}$ \\
\hline
\end{tabular}

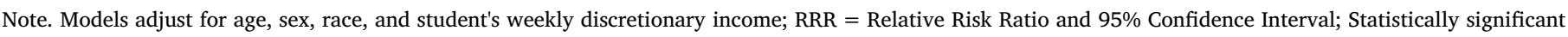
estimates appear in bold; ${ }^{*} p<.05$, ${ }^{* *} p<.01,{ }^{* * *} p<.001$, weighted estimates

multiple tobacco product use among high school youth in NC. Whereas MTP users differed from non-users of tobacco on factors at all levels of influence, fewer differences emerged between MTP and single product users. As such, in comparison to non-users of tobacco, MTP users had weaker tobacco-related harm perceptions, greater perceived social benefits of smoking (intrapersonal factors), higher relative risk of having family members and friends who use tobacco, and of exposure to smoking at home or family vehicle (interpersonal and primary groups factors). MTP users also had a higher risk of exposure to secondhand vapor from e-cigarettes at community settings (institutional and community factors), and a higher relative risk of being receptive to tobacco marketing (tobacco policy factors). In contrast, no differences were observed between MTP and single product users in harm perceptions of tobacco, perceived social benefits of smoking, family smoking or exposure to smoking at home or family vehicle. MTP users differed from single product users most notably in their higher relative risk of having friends who use tobacco, exposure to secondhand vapor from e-cigarettes, and in being more receptive to tobacco marketing.

Notably, single and MTP users did not differ on intrapersonal factors and had comparable tobacco-related harm perceptions. These findings are consistent with previous studies showing that youth tobacco users are less likely to perceive risks from their use than non-users (Ambrose, Rostron, Johnson, et al., 2014; Barrington-Trimis, Berhane, Unger, et al., 2015). A key issue is to understand youth harm perceptions of OTPs, particularly those most commonly used by single product and MTP users (Osman et al., 2018). As we show, OTPs (including e-cigarettes, cigar products, smokeless tobacco, pipe, and hookah) are commonly used by youth MTP users. Evidence supports that youth perceive OTPs as less harmful than cigarettes, (Jordan \& Delnevo, 2010; Primack, Walsh, Bryce, et al., 2009) and that OTPs harm perceptions are weaker among tobacco users as compared to non-users. For example, in Cooper et al., 2016 youth MTP users were more likely to believe that cigars, e-cigarettes, hookah, and smokeless tobacco are not at all harmful compared to non-users (Cooper et al., 2016). Few other studies also showed weaker harm perceptions of e-cigarettes among tobacco users than non-users (Ambrose et al., 2014; Amrock, Zakhar, Zhou, et al., 2014). Our results suggest that youth targeted communication campaigns should broaden their focus from cigarette specific prevention messages to communications clarifying OTP health risks that are equal to or greater than those of cigarettes. Furthermore, rather than communicating about the health effects of tobacco use in general, or focusing on a single product like cigarettes, campaigns may need to develop clear messages about the harmful health effects of concurrent use of multiple tobacco products.

Our findings underscore the importance of social influences to MTP use. Most notably, MTP users appear to have the highest risk of having friends who use tobacco. Peer influences and normative beliefs have been recognized as one aspect of the social environment that contributes to initiation of and sustaining cigarette smoking (BarringtonTrimis et al., 2015; Nasim et al., 2012). Limited evidence also suggests that peer use of OTPs is a major predictor of adolescent use of alternative tobacco products such as e-cigarettes. (Barrington-Trimis et al., 2015). Thus, peer use of OTPs may play a role in encouraging multiple product use (Cooper et al., 2016) particularly because some OTPs (e.g., hookah, e-cigarettes, Juul) are perceived as social and interactive products used while relaxing with friends and family (Maziak, Ward, 
Soweid, et al., 2004). A challenging aspect of human behavior, social influence of peers and family, has yet to be addressed in tobacco related interventions.

Neither single product users nor MTP users differed from non-tobacco users with regard to exposure to secondhand smoke in community settings. Single and MTP users, however, were more at risk than non-users of exposure to secondhand vapor from e-cigarettes. Whereas smoke free policies has been effective in reducing secondhand smoke from cigarettes, these laws do not extend to e-cigarettes. Indeed, one of the key reasons for e-cigarette use, particularly among smokers, is the ability to use them in places were smoking is banned (Kong, Morean, Cavallo, et al., 2014). Furthermore, our data illuminate that, in 2015, ecigarettes were the most commonly used product among youth single product and MTP users. Given how ubiquitous e-cigarette use is among youth, this level of exposure to secondhand vapor is not surprising and is likely linked to the user's own or peers' vaping sessions. Concerns have been raised about potential unintended consequences of regulations that would restrict e-cigarette use, leading youth to continue smoking combustible products (Kenkel, 2016). Notwithstanding these concerns, secondhand vapor from unregulated e-cigarette products contains nicotine, and other potentially harmful flavoring additives, (Benowitz, 2014) and should be restricted in settings that children and youth attend in NC and elsewhere.

Receptivity to items with tobacco marketing was strongly associated with MTP use in comparison to both non-use and single product use. This strong association endured even after adjusting for a myriad of other risk factors including demographics, harm perceptions, and social influences. Whereas previous studies showed that receptivity to tobacco advertising is associated with tobacco use and progression toward use in adolescence (Gilpin, White, Messer, et al., 2007; Pierce et al., 2017; Pierce, Sargent, Portnoy, et al., 2018; Sargent, Dalton, Beach, et al., 2000), this is the first study to show a strong association with MTP use and suggests a need to eliminating promotional campaigns for all tobacco products and OTPs.

\section{Limitations}

Data on tobacco use were self-reported and may be subject to related biases (e.g., recall or response biases). The NC YTS sample excluded youth dropouts or youth not enrolled in school, who may have higher rates of tobacco use. Thus, the findings from this study may not generalize to all high school-aged youth in NC or nationally. Single product use and MTP use estimates were calculated based on use data for 10 tobacco products. Students with missing data on any of these products were excluded from the analytic sample. Missing data on tobacco use variables were small however $(0.3 \%-3.5 \%$ for all products, $6 \%$ for smokeless tobacco), hence we expect little or no impact on our estimates. The NC YTS survey has been administered to middle and high school students every two years since 1999. Questions are kept at a readability level and length that are appropriate for a young audience. Thus, some survey questions, such as those assessing harm perceptions, are general in nature and do not capture youth harm perceptions of specific tobacco products. Lastly, due to small sample sizes, we were unable to distinguish between Asians, American Indians or Alaska Natives, and Native Hawaiians or Other Pacific Islanders and those groups were combined into one race group. This classification may have prevented us from observing how each group differed relative to Whites, Blacks, and Hispanics as previous research has shown, for example, that Asian American have the lowest rates of tobacco use (Ellickson, Orlando, Tucker, et al., 2004). Students who selected multiple race groups were assigned to a single race category based on a predetermined assignment rule. This approach to race categorization may have introduced some measurement error by retaining incomplete information about respondents' reported races.

\section{Conclusions}

In an evolving and diversified tobacco product marketplace, it is imperative to prioritize protecting youth from becoming dependent on tobacco products. Understanding the unique risk factors that drive multiple tobacco product use in youth may help develop tailored novel strategies and regulations to prevent youth uptake of traditional and emerging tobacco products. This study underscores the importance of examining tobacco use risk factors at multiple levels of influence and shows that interpersonal factors such as social influences, community exposures, and receptivity to tobacco marketing affect multiple tobacco product use above and beyond the effects of intrapersonal factors such as demographics, harm perceptions, and beliefs about the social benefits of smoking. Interventions that specifically target youth risk and harm perceptions of OTPs and of concurrent tobacco product use, and protect youth from social, peer, and industry influences may help prevent multiple tobacco product use in youth.

\section{Role of funding sources}

Grant number P50CA180907 from the National Cancer Institute and FDA Center for Tobacco Products (CTP) supported the authors' time writing this manuscript. Data collection for the North Carolina Youth Tobacco Survey and Ms. Heck's effort on this manuscript were supported by the grant or cooperative agreement no. DP005974 funded by the Centers for Disease Control and Prevention. The content of this manuscript is solely the responsibility of the authors and does not necessarily represent the official views of the NIH, the Food and Drug Administration, the Centers for Disease Control and Prevention, or the US Department of Health and Human Services.

\section{Contributors}

Author AO conceived of the research idea, conducted the statistical analyses, and wrote the first draft of the manuscript. Authors SK, LR, $\mathrm{CH}$, and AG reviewed multiple drafts of the manuscript and provided feedback and comments to improve it. All authors contributed to, and have approved the final manuscript.

\section{Declaration of Competing Interest}

None.

\section{References}

Ali, M., Gray, T. R., Martinez, D. J., et al. (2016). Risk profiles of youth single, dual, and poly tobacco users. Nicotine \& Tobacco Research, 18, 1614-1621.

Ambrose, B. K., Rostron, B. L., Johnson, S. E., et al. (2014). Perceptions of the relative harm of cigarettes and e-cigarettes among US youth. American Journal of Preventive Medicine, 47, S53-S60.

Amrock, S. M., Zakhar, J., Zhou, S., et al. (2014). Perception of e-cigarette harm and its correlation with use among US adolescents. Nicotine \& Tobacco Research, 17, 330-336.

Apelberg, B. J., Corey, C. G., Hoffman, A. C., et al. (2014). Symptoms of tobacco dependence among middle and high school tobacco users. American Journal of Preventive Medicine, 47, S4-S14.

Arrazola, R. A., Singh, T., Corey, C. G., et al. (2015). Tobacco use among middle and high school students-United States, 2011-2014. MMWR. Morbidity and Mortality Weekly Report, 64, 381-385.

Baker, F., Ainsworth, S. R., Dye, J. T., et al. (2000). Health risks associated with cigar smoking. Jama, 284, 735-740.

Barrington-Trimis, J. L., Berhane, K., Unger, J. B., et al. (2015). Psychosocial factors associated with adolescent electronic cigarette and cigarette use. Pediatrics, 136(2), 308-317.

Benowitz, N. L. (2014). Emerging nicotine delivery products. Implications for public health. Annals of the American Thoracic Society, 11, 231-235.

Campaign for Tobacco Free Kids. Key state-specific Tobacco-Related Data \& Rankings. (2019). Available at: https://www.tobaccofreekids.org/assets/factsheets/0176.pdf (Accessed May 23 2019).

Campaign for Tobacco Free Kids. Tobacco-growing states in the USA. (2014). Available at: https://www.tobaccofreekids.org/assets/factsheets/0125.pdf (Accessed May 23 2019) . 
Cooper, M., Creamer, M. R., Ly, C., et al. (2016). Social norms, perceptions and dual/poly tobacco use among Texas youth. American Journal of Health Behavior, 40, 761-770.

Dwyer, J. B., McQuown, S. C., \& Leslie, F. M. (2009). The dynamic effects of nicotine on the developing brain. Pharmacology \& Therapeutics, 122, 125-139.

Ellickson, P. L., Orlando, M., Tucker, J. S., et al. (2004). From adolescence to young adulthood: Racial/ethnic disparities in smoking. American Journal of Public Health, 94, 293-299.

El-Toukhy, S., \& Choi, K. (2016). A risk-continuum categorization of product use among US youth tobacco users. Nicotine \& Tobacco Research, 18, 1596-1605.

Fix, B. V., O'Connor, R. J., Vogl, L., et al. (2014). Patterns and correlates of polytobacco use in the United States over a decade: NSDUH 2002-2011. Addictive Behaviors, 39, 768-781.

Gilpin, E. A., \& Pierce, J. P. (2003). Concurrent use of tobacco products by California adolescents. Preventive Medicine, 36, 575-584.

Gilpin, E. A., White, M. M., Messer, K., et al. (2007). Receptivity to tobacco advertising and promotions among young adolescents as a predictor of established smoking in young adulthood. American Journal of Public Health, 97, 1489-1495.

Horn, K., Pearson, J. L., \& Villanti, A. C. (2016). Polytobacco use and the "customization generation"-New perspectives for tobacco control. Journal of Drug Education, 46, 51-63.

Jordan, H. M., \& Delnevo, C. D. (2010). Emerging tobacco products: Hookah use among New Jersey youth. Preventive Medicine, 51, 394-396.

Kenkel, D. S. (2016). Healthy innovation: Vaping, smoking, and public policy. Journal of Policy Analysis and Management, 35, 473-479.

Kong, G., Morean, M. E., Cavallo, D. A., et al. (2014). Reasons for electronic cigarette experimentation and discontinuation among adolescents and young adults. Nicotine \& Tobacco Research, 17, 847-854.

Kowitt, S. D., Patel, T., Ranney, L. M., et al. (2015). Poly-tobacco use among high school students. International Journal of Environmental Research and Public Health, 12, 14477-14489.

Lauterstein, D., Hoshino, R., Gordon, T., et al. (2014). The changing face of tobacco use among United States youth. Current Drug Abuse Reviews, 7, 29-43.

Lee, Y. O., Hebert, C. J., Nonnemaker, J. M., et al. (2015). Youth tobacco product use in the United States. Pediatrics, 135, 409-415.

Mantey, D. S., Cooper, M. R., Clendennen, S. L., et al. (2016). E-cigarette marketing exposure is associated with e-cigarette use among US youth. Journal of Adolescent Health, 58, 686-690.

Maziak, W., Ward, K., Soweid, R. A., et al. (2004). Tobacco smoking using a waterpipe: A re-emerging strain in a global epidemic. Tobacco Control, 13, 327-333.

McCullough, A., Ranney, L. M., Simons, D. J., et al. (2018). "The job has become advocating for the job": Threats to funding dramatically influence program outcomes. American Journal of Health Promotion, 32, 861-864.

Nasim, A., Blank, M. D., Cobb, C. O., et al. (2012). Patterns of alternative tobacco use among adolescent cigarette smokers. Drug \& Alcohol Dependence, 124, 26-33.

NC Health and Human Services. North Carolina youth tobacco survey. (2019). Available at: http://tobaccopreventionandcontrol.ncdhhs.gov/data/yts/index.htm (Accessed May 24 2019) .

Osman, A., Kowitt, S., Ranney, L. M., et al. (2018). Trends and racial disparities in mono, dual, and poly use of tobacco products among youth. Nicotine \& Tobacco Research, 20, S22-S30.

Pierce, J. P., Sargent, J. D., Martha, M., et al. (2017). Receptivity to tobacco advertising and susceptibility to tobacco products. Pediatrics, 139, e20163353.

Pierce, J. P., Sargent, J. D., Portnoy, D. B., et al. (2018). Association between receptivity to tobacco advertising and progression to tobacco use in youth and young adults in the PATH study. JAMA Pediatrics, 172(5), 444-451.

Primack, B. A., Walsh, M., Bryce, C., et al. (2009). Water-pipe tobacco smoking among middle and high school students in Arizona. Pediatrics, 123, e282-e288.

Sallis, J. F., Owen, N., \& Fisher, E. (2015). Ecological models of health behavior. Health behavior: Theory, research, and practice 5 th ed (pp. 43-64). San Francisco: Jossey-Bass.

Sargent, J. D., Dalton, M., Beach, M., et al. (2000). Effect of cigarette promotions on smoking uptake among adolescents. Preventive Medicine, 30, 320-327.

Soneji, S., Sargent, J., \& Tanski, S. (2016). Multiple tobacco product use among US adolescents and young adults. Tobacco Control, 25, 174-180.

Teo, K. K., Ounpuu, S., Hawken, S., et al. (2006). Tobacco use and risk of myocardial infarction in 52 countries in the INTERHEART study: A case-control study. The Lancet, 368, 647-658.

Tomar, S. L., Alpert, H. R., \& Connolly, G. N. (2010). Patterns of dual use of cigarettes and smokeless tobacco among US males: Findings from national surveys. Tobacco Control, 19, 104-109.

Wang, T. W., Gentzke, A., Sharapova, S., et al. (2018). Tobacco product use among middle and high school students-United States, 2011-2017. Morbidity and Mortality Weekly Report, 67, 629.

Wetter, D. W., McClure, J. B., de Moor, C., et al. (2002). Concomitant use of cigarettes and smokeless tobacco: Prevalence, correlates, and predictors of tobacco cessation. Preventive Medicine, 34, 638-648. 